\title{
Vitamins, selenium, iron, and coronary heart disease risk in Indians, Malays, and Chinese in Singapore
}

\author{
Kenneth Hughes, Choon-Nam Ong
}

\begin{abstract}
Study objective-To examine the hypothesis that the higher rates of coronary heart disease (CHD) in Indians (South Asians) compared with Malays and Chinese is partly because of differences in antioxidants (vitamins $A, C$, and $E$, and selenium) and pro-oxidants (iron).

Design-Cross sectional study of the general population.

Setting-Singapore.

Participants-Random sample of 941 persons aged 30 to 69 years.

Main results-There were moderate correlations between vitamin $A$ and vitamin $E$, and between these vitamins and selenium. Mean plasma vitamins $A$ and $E$ were similar by ethnic group. Vitamin A concentration for Indians were (men 0.66 and women $0.51 \mathrm{mg} / \mathrm{l}$ ), Malays (men 0.67 and women $0.54 \mathrm{mg} / \mathrm{l}$ ), and Chinese (men 0.68 and women $0.52 \mathrm{mg} / 1)$. Vitamin $E$ concentrations for Indians were (men 12.9 and women $12.8 \mathrm{mg} / \mathrm{l}$ ), Malays (men 13.6 and women $13.3 \mathrm{mg} / \mathrm{l}$ ), and Chinese (men 12.6 and women $12.6 \mathrm{mg} / \mathrm{l})$. In contrast, mean plasma vitamin $C$ concentrations were lower in Indians (men 5.7 and women $6.9 \mathrm{mg} / \mathrm{l}$ ) and Malays (men 5.1 and women $6.4 \mathrm{mg} / \mathrm{l}$ ) than Chinese (men 6.3 and women $8.4 \mathrm{mg} / \mathrm{l})$. Mean serum selenium was lower in Indians (men 117 and women $115 \mu \mathrm{g} / \mathrm{l}$ ) than Malays (men 122 and women $122 \mu \mathrm{g} / \mathrm{l}$ ) and Chinese (men 126 and women $119 \mu \mathrm{g} / 1)$. Mean serum ferritin was much lower in Indians (men 132 and women $50 \mu \mathrm{g} / 1$ ) than Malays (men 175 and women $85 \mu \mathrm{g} / 1$ ) and Chinese (men 236 and women $92 \mu \mathrm{g} / 1)$.
\end{abstract}

Main conclusions-Lower vitamin $\mathrm{C}$ and selenium in Indians, particularly in combination, could play a part in their increased risk of CHD. Vitamins $A$ and $E$, and ferritin (iron) have no such role. Lower vitamin $C$ in Indians and Malays is probably because of its destruction by more prolonged cooking. In Indians, lower selenium is probably because of a lower dietary intake and the much lower ferritin to a lower dietary intake of iron and its binding by phytates.

(F Epidemiol Community Health 1998;52:181-185)

Indians or South Asians (that is, people from the Indian subcontinent) have been found in a number of countries to be particularly suscep- tible to coronary heart disease (CHD). ${ }^{1}$ This is not because of the classic risk factors of cigarette smoking, hypertension, and hypercholesterolaemia. ${ }^{1}$ Abdominal obesity, insulin resistance with hyperinsulinaemia, and Syndrome X may be part of the explanation. ${ }^{1}$ However, there may be other risk factors that need to be identified. Finding the reasons for the increased susceptibility of Indians to CHD is not only of importance to Indians themselves but will provide important information on the aetiology of the disease.

There is strong evidence that oxidative free radicals have a role in the development of degenerative diseases including CHD. ${ }^{2}$ Oxidative free radicals increase the peroxidation of low density lipoprotein thereby increasing its uptake by macrophages with increased foam cell formation and atherosclerosis, ${ }^{3}$ though other mechanisms may exist. ${ }^{4}$ Anti-oxidants in the diet include vitamin A (carotenoids, which are metabolised to retinol), vitamin C (ascorbate), vitamin $\mathrm{E}$ (tocopherol), and selenium, which is an integral part of the antioxidant enzyme glutathione peroxidase.

There is evidence that anti-oxidant vitamins are protective against CHD from both laboratory ${ }^{5}$ and observational epidemiological ${ }^{6}$ studies, with strong evidence for the benefits of fresh fruits and vegetables. ${ }^{7}$ However, the evidence for the beneficial effects of antioxidants is considered inconclusive. ${ }^{489}$ No benefits have been found for vitamins $\mathrm{A}$ and $\mathrm{E}$ supplementation on cardiovascular disease or cancer in the Alpha-Tocopherol, Beta Carotene (ATBC) Cancer Prevention Study, ${ }^{10}$ the Physicians' Health Study, ${ }^{11}$ and the BetaCarotene and Retinol Efficacy Trial (CARET). ${ }^{12}$ These trials were of short duration, however, and examined the possible benefits of vitamin supplementation rather than the possible harmful effects of low vitamin intake. There is epidemiological evidence for the beneficial effect of selenium particularly from Finland, ${ }^{13}{ }^{14}$ though again it is considered inconclusive. $^{15}$

Iron, another dietary constituent, is a pro-oxidant and high concentrations of blood ferritin, which measures stored iron, is a possible risk factor for CHD. It has been proposed that the sex difference in CHD is a result of differences in ferritin values. ${ }^{16}$ It has been concluded on present evidence, however, that the role of iron on CHD is undecided. ${ }^{15} 17$

Singapore is an island state with a population of 3.3 million people composed of Chinese $76 \%$, Malays $14 \%$, Indians $7 \%$, and others 3\% 
whose origins have been described, with $80 \%$ of Indians originating from the southern states of India (Tamil Nadu or Kerala) and Sri Lanka ${ }^{18}$ Indians have much more CHD (but not more cerebrovascular diasease) than $\mathrm{Ma}$ lays and Chinese especially in the younger age groups, with Malays having more than Chinese. ${ }^{18}$ The Singapore Thyroid and Heart Study found that the greater susceptibility of Indians to CHD could not be explained by cigarette smoking, hypertension, and hypercholesterolaemia, ${ }^{19}$ physical activity ${ }^{20}$ or general obesity, ${ }^{21}$ although Indians did have more diabetes and lower HDL-cholesterol, ${ }^{19}$ with the latter not explained by alcohol consumption. ${ }^{22}$ In Singapore the ethnic groups live in the same environment with the only difference in lifestyles being their diets, suggesting that the cause of the increased susceptibility of Indians to $\mathrm{CHD}$ is in their genetic make up or diet, or both.

The National University of Singapore Heart Study is a further cross sectional survey on the general population, carried out to examine cardiovascular risk factors, in particular the newer ones not studied in the Singapore Thyroid and Heart Study. A previous paper from the former study reported that Indians compared with Malays and Chinese had more abdominal obesity, insulin resistance with hyperinsulinaemia, and certain components of Syndrome X, together with higher serum concentration of lipoprotein (a), which could partly explain their increased susceptibility to $\mathrm{CHD} .^{23}$ However, other mechanisms may exist. The Indian diet is distinctive, entailing prolonged cooking at high temperatures, and could be different in its content of anti-oxidants and pro-oxidants. This paper examines ethnic differences in blood vitamins ( $A, C$, and $E$ ), selenium, and ferritin.

\section{Methods}

SAMPLE

The National University of Singapore Heart Study was a cross sectional survey of a random sample of persons aged 30 to 69 years from the general population of Singapore. The sampling has been described in detail. ${ }^{23}$ There was a response rate of $71.2 \%$, with 961 responders aged between 30 and 69 years. Of these, 20 persons did not have vitamin and mineral measurements because of the unavailability of the technician on their clinic days, but this was

Table 1 Pearson partial correlation coefficients ( $p$ values), adjusted for age, between plasma vitamins and serum minerals for 468 men and 473 women aged 30 to 69 years

\begin{tabular}{llllll}
\hline & Vitamin A & Vitamin $E$ & Vitamin $C$ & Selenium & \multicolumn{1}{l}{ Ferritin } \\
\hline Vitamin A & & & & & \\
$\quad$ Men & & $0.26(<0.01)$ & $-0.07(0.12)$ & $0.19(<0.01)$ & $0.05(0.29)$ \\
$\quad$ Women & & $0.34(<0.01)$ & $0.05(0.25)$ & $0.17(<0.01)$ & $0.12(0.01)$ \\
Vitamin E & & & & \\
$\quad$ Men & $0.26(<0.01)$ & & $0.03(0.58)$ & $0.10(0.03)$ & $0.07(0.15)$ \\
$\quad$ Women & $0.34(<0.01)$ & & $0.04(0.44)$ & $0.15(<0.01)$ & $0.09(0.06)$ \\
Vitamin C & & & & $0.09(0.05)$ & $0.01(0.99)$ \\
$\quad$ Men & $-0.07(0.12)$ & $0.03(0.58)$ & & $-0.07(0.14)$ & $-0.11(0.02)$ \\
$\quad$ Women & $0.05(0.25)$ & $0.04(0.44)$ & & $0.08(0.08)$ \\
Selenium & $0.19(<0.01)$ & $0.10(0.03)$ & $0.09(0.05)$ & & $0.12(<0.01)$ \\
$\quad$ Men & $0.17(<0.01)$ & $0.15(<0.01)$ & $-0.07(0.14)$ & & \\
$\quad$ Women & & & & & \\
Ferritin & & & & \\
$\quad$ Men & $0.05(0.29)$ & $0.07(0.15)$ & $0.01(0.99)$ & $0.08(0.08)$ & \\
$\quad$ Women & $0.12(0.01)$ & $0.09(0.06)$ & $-0.11(0.02)$ & $0.12(<0.01)$ & \\
\hline
\end{tabular}

in a purely random way. Hence measurements were performed on 941 persons aged between 30 and 69 years.

\section{PROCEDURES}

All clinics were held on weekday mornings between 0900 and 1200 hours (from June 1993 to December 1995) with both sexes and three ethnic groups seen concurrently. The subjects were asked to fast from 2100 hours the previous evening. A questionnaire was administered by the same investigator trained in interview techniques and included questions on age, sex, and ethnic group (classification previously described ${ }^{18}$ ).

Venous blood specimens were taken with the subject in a sitting position using venoject vacuum containers with minimum venous stasis. Specimens of $4.0 \mathrm{ml}$ of blood were each taken in vacutainers containing EDTA and heparin as anticoagulants and covered with aluminium foil to prevent admission of light, and these were transported on ice to the laboratory where the blood was centrifuged and measurements made on plasma by automated high performance liquid chromatography. On the EDTA tube, measurement of plasma vitamin C (ascorbic acid), ${ }^{24}$ was performed immediately, while on the heparinised tube, measurements of plasma vitamin A (retinol), ${ }^{25}$ and plasma vitamin $\mathrm{E}$ ( $\alpha$ tocopherol), ${ }^{25}$ were performed in batches within two weeks after storing at $-70^{\circ} \mathrm{C}$. On specimens collected in plain vacutainers serum ferritin was measured in batches weekly after storing at $-20^{\circ} \mathrm{C}$ by microparticle enzyme immunoassay using $\mathrm{Ab}$ bott IMX, while serum selenium was measured by Zeeman atomic absorption spectrophotometry in batches within two weeks after storing at $-70^{\circ} \mathrm{C}$.

ANALYSIS

The mean ages were similar by sex and ethnic group; nevertheless age adjustment was performed. Pearson product moment partial correlation coefficients adjusted for age between the vitamins and minerals were calculated on SPSS. Means were age adjusted by analysis of covariance using the GLM Procedure of SAS. As cigarette smoking is known to reduce vitamin $\mathrm{C},{ }^{2}$ this vitamin was also compared by ethnic group in non-smokers. Ferritin was also examined in pre-menopausal and post-menopausal women, as there is iron loss with menstruation. All significance testing was two tailed.

\section{Results}

Table 1 shows the correlations in the subjects of the vitamins and minerals. The only consistent, statistically significant, and reasonably strong correlations were moderate ones between vitamin $\mathrm{A}$ and vitamin $\mathrm{E}$ and slight/ moderate ones between these two vitamins and selenium.

Table 2 shows the mean concentrations of vitamins and minerals in the three ethnic groups. Vitamin A values (higher in men than women) were very similar by ethnic group. Vitamin $\mathrm{E}$ values (similar in the two sexes) 
Table 2 Means (95\% confidence intervals), age adjusted by analysis of covariance, of vitamins and minerals for Indians (I), Malays (M), and Chinese (C), by sex, for age group 30 to 69 years

\begin{tabular}{|c|c|c|c|c|c|c|}
\hline & \multirow{2}{*}{$\begin{array}{l}\text { Indians }(\text { men }=166 \text {, } \\
\text { women }=166)\end{array}$} & \multirow{2}{*}{$\begin{array}{l}\text { Malays (men }=144 \text {, } \\
\text { women }=142)\end{array}$} & \multirow{2}{*}{$\begin{array}{l}\text { Chinese }(\text { men }=158, \\
\text { women }=165)\end{array}$} & \multicolumn{3}{|c|}{ Significance, $p$ value } \\
\hline & & & & $I v M$ & $I v C$ & $M v C$ \\
\hline \multicolumn{7}{|c|}{ Plasma vitamin A (mg/l) } \\
\hline Men & $0.66(0.64,0.68)$ & $0.67(0.65,0.69)$ & $0.68(0.66,0.70)$ & 0.58 & 0.34 & 0.70 \\
\hline Women & $0.51(0.49,0.53)$ & $0.54(0.52,0.56)$ & $0.52(0.50,0.54)$ & 0.19 & 0.63 & 0.39 \\
\hline \multicolumn{7}{|c|}{ Plasma vitamin E (mg/l) } \\
\hline Men & $12.9(12.4,13.4)$ & $13.6(13.0,14.2)$ & $12.6(12.0,13.2)$ & 0.11 & 0.46 & 0.02 \\
\hline Women & $12.8(12.3,13.3)$ & $13.3(12.7,13.9)$ & $12.6(12.0,13.1)$ & 0.18 & 0.67 & $<0.08$ \\
\hline \multicolumn{7}{|c|}{ Plasma vitamin $\mathrm{C}(\mathrm{mg} / \mathrm{l})$} \\
\hline Men & $5.7(5.2,6.2)$ & $5.1(4.6,5.6)$ & $6.3(5.8,6.8)$ & 0.12 & 0.09 & $<0.01$ \\
\hline Women & $6.9(6.4,7.4)$ & $6.4(5.8,7.0)$ & $8.4(7.9,8.9)$ & 0.20 & $<0.01$ & $<0.01$ \\
\hline${ }^{\star}$ Men & $6.1(5.6,6.6)$ & $5.6(5.1,5.7)$ & $7.3(6.8,7.8)$ & 0.35 & 0.01 & $<0.01$ \\
\hline ^Women & $6.8(6.5,7.1)$ & $6.4(6.1,6.7)$ & $8.4(8.1,8.7)$ & 0.21 & $<0.01$ & $<0.01$ \\
\hline \multicolumn{7}{|c|}{ Serum selenium $(\mu \mathrm{g} / \mathrm{l})$} \\
\hline Men & $117(115,119)$ & $122(120,124)$ & $126(124,128)$ & 0.01 & $<0.01$ & 0.02 \\
\hline Women & $115(113,117)$ & $122(120,124)$ & $119(117,121)$ & $<0.01$ & 0.01 & 0.18 \\
\hline \multicolumn{7}{|c|}{ Serum ferritin $(\mu \mathrm{g} / \mathrm{l})$} \\
\hline Men & $132(117,147)$ & $175(158,192)$ & $236(221,251)$ & $<0.01$ & $<0.01$ & $<0.01$ \\
\hline Women & $50(35,65)$ & $85(68,101)$ & $92(77,107)$ & $<0.01$ & $<0.01$ & 0.54 \\
\hline tWomen & $30(14,46)$ & $55(38,72)$ & $61(44,78)$ & 0.04 & 0.01 & 0.65 \\
\hline ‡Women & $83(55,111)$ & $140(109,171)$ & $141(115,167)$ & $<0.01$ & $<0.01$ & 0.93 \\
\hline
\end{tabular}

^Non-smokers, † pre-menopausal (30-49 years), ‡ post-menopausal (50-69 years).

were highest in Malays, then Indians, and then Chinese for both sexes, though the differences were small and only those between Malays and Chinese were statistically significant.

Vitamin $\mathrm{C}$ values (higher in women than men) show ethnic differences, being higher in Chinese than Indians and Malays for both sexes (table 2). For men, vitamin $\mathrm{C}$ was higher in Chinese than Indians by $0.6 \mathrm{mg} / \mathrm{l}$ and than Malays by $1.2 \mathrm{mg} / \mathrm{l}$, while for women the differences were $1.5 \mathrm{mg} / 1$ and $2.0 \mathrm{mg} / 1$ respectively. For non-smokers, the same ethnic differences were present. For men, higher concentrations of vitamin $\mathrm{C}$ were present for all three ethnic groups in non-smokers than in all men.

Selenium (similar in the two sexes) also shows ethnic differences (table 2). For men, selenium was highest in Chinese, then Malays, and then Indians, while for women it was not significantly different in Chinese and Malays, who both had higher concentrations than Indians. For men, selenium was lower in Indians than Malays by $5 \mu \mathrm{g} / 1$ and than Chinese by 9 $\mu \mathrm{g} / \mathrm{l}$, while for women the differences were 7 $\mu \mathrm{g} / 1$ and $4 \mu \mathrm{g} / 1$ respectively.

Ferritin (considerably higher in men than women for all three ethnic groups) shows pronounced ethnic differences (table 2). For both sexes, Indians had much lower values than Chinese and Malays. For men, ferritin concentrations for Indians were less than Malays by 43 $\mu \mathrm{g} / 1$ and than Chinese by $104 \mu \mathrm{g} / 1$ and Malays had lower values than Chinese by $61 \mu \mathrm{g} / \mathrm{l}$. For women, concentrations in Indians were less than Malays by $35 \mu \mathrm{g} / \mathrm{l}$ and than Chinese by 42 $\mu \mathrm{g} / \mathrm{l}$, but there was no statistically significant difference between Malays and Chinese. These same ethnic differences for ferritin were present in pre-menopausal (30 to 49 years) and post-menopausal (50 to 69 years) women.

\section{Discussion}

This study in Singapore examines the possible roles of anti-oxidants and pro-oxidants in the differential risk from CHD between Indians, Malays, and Chinese and is the first to examine these as a possible contributory cause of the increased susceptibility of Indians to CHD.
The blood concentrations of vitamins and minerals in people will vary with changes in their dietary intake, though it should be noted that the subjects in this study had been fasting for at least 12 hours. Despite any individual variation, on a population basis blood concentrations of these vitamins and minerals will measure ethnic differences in blood levels and dietary intake.

In 1993 a food consumption survey on a number of dietary constituents (including vitamin A) was carried out in Singapore on a random sample of the general population aged 18 to 69 years using both the methods of 24-Hour Dietary Recall and 3-Day Food Intake Records. ${ }^{26}$

Plasma lipids influence tocopherol concentrations so that the vitamin E:cholesterol ratio is sometimes used. ${ }^{27}$ However, total cholesterol concentrations are similar in the three ethnic groups, ${ }^{23}$ so that this correction would make no difference to ethnic comparisons. Plasma concentrations of vitamins $\mathrm{A}$ and $\mathrm{E}$ were correlated, which is no doubt because of common dietary sources. ${ }^{28} 29$ The consumption survey in Singapore found that intakes of vitamin A were higher in men than women with no important ethnic differences. ${ }^{26}$ The finding of higher plasma concentrations of vitamin $\mathrm{A}$ in men than women and no ethnic differences are consistent with the findings on diet. Similar values of blood vitamins $\mathrm{A}$ and $\mathrm{E}$ by ethnic group indicate that these anti-oxidants have no role in the increased susceptibility of Indians to CHD compared with Malays and Chinese. Values of vitamins $A$ and $E$ in Singapore are comparable to those reported in US populations. ${ }^{28} 29$

The lower plasma concentrations of vitamin $\mathrm{C}$ in smokers was shown in men by higher levels in non-smokers than all men. There was little difference for women because of the very small proportion of women who smoke in Singapore. Lower concentrations of vitamin C in smokers is both a result of lower intake and of a higher metabolic turnover. ${ }^{30}$ Plasma concentrations of vitamin $\mathrm{C}$ were higher in women than men, which is consistent with findings 
elsewhere with women having higher levels than men despite similar dietary intakes. ${ }^{30}$

Plasma concentrations of vitamin C were lower in Malays and Indians than Chinese for both sexes, both in all persons and in non-smokers. Most vitamin $\mathrm{C}$ in the diet comes from fruits and vegetables. ${ }^{30}$ It is unlikely that Indians and Malays have a lower dietary intake of these foods, particularly as dietary intake and plasma values of vitamin $\mathrm{A}$ and plasma values of vitamin $\mathrm{E}$ are similar by ethnic group. Unlike vitamins $\mathrm{A}$ and $\mathrm{E}$, however, vitamin $\mathrm{C}$ is water soluble and easily destroyed by heat treatment. ${ }^{31}$ There is more prolonged cooking at higher temperatures with Indian and Malay dishes such as curries compared with the typical Chinese stir fried dishes, and furthermore in the latter cooking oil will protect vitamin $\mathrm{C}$ in food. Hence there will be more destruction of vitamin $\mathrm{C}$ in Indian and Malay cooking than Chinese cooking resulting in lower blood concentrations. Lower blood vitamin $\mathrm{C}$ in Indians and Malays may contribute to their higher rates of $\mathrm{CHD}$ compared with Chinese. It has been found that serum ascorbate concentration was inversely related to haemostatic factors fibrinogen and factor VIIc, ${ }^{32}$ suggesting that low vitamin C may also be a risk factor for $\mathrm{CHD}$ by increasing thrombosis. However, no important ethnic differences have been found in Singapore for fibrinogen or factor VIIc. ${ }^{23}$ Mean concentrations of vitamin $\mathrm{C}$ for all three ethnic groups in Singapore are lower than have been reported for US populations, and are at the lower end of the normal range of 4.0 to $15.0 \mathrm{mg} / \mathrm{l}^{30}$

Serum selenium concentrations showed little sex differences, with Indians having lower levels than Malays and Chinese in both sexes. The richest food sources of selenium are meats and seafoods, followed by cereals, and dairy products. ${ }^{33}$ Indians have a more vegetarian diet than the other two ethnic groups; the food consumption survey found that $7.8 \%$ of Indians but no Malays or Chinese were strict vegetarians with a further $5.1 \%$ of Indians and only $0.8 \%$ of Malays and $0.9 \%$ of Chinese having a red meat free diet. ${ }^{26} \mathrm{~A}$ lower intake of meats and seafoods in Indians is probably the explanation for their lower blood concentrations of selenium, which could play a part in their greater susceptiblity to CHD. In the USA, average blood selenium values ranged from 160 to $260 \mu \mathrm{g} / 1$ with values in areas with low and marginally adequate levels of soil selenium being 119 and $134 \mu \mathrm{g} / 1$ respectively, ${ }^{33}$ indicating that values in Singapore are on the low side.

Serum ferritin was lower in women than men, which is caused by menstrual loss of iron though post-menopausal women still had lower levels than men. Indians had much lower serum ferritin values for both sexes, which could be because of reduced dietary intake or impaired absorption. It was found in women in Britain that Indians had lower values of serum ferritin than the white, black, and oriental populations, which was considered probably to be a result of reduced iron intake. ${ }^{34}$ Dietary iron is obtained mainly from red meats, but also from some
KEY POINTS

- Indians (South Asians) have more coronary heart disease (CHD) than Malays and Chinese in Singapore.

- Indians have lower blood concentrations of vitamin $\mathrm{C}$ and selenium (antioxidants), which may contribute to their increase risk of CHD.

- There are no ethnic differences for blood concentrations of vitamins A and E.

- Indians have lower blood concentrations of ferritin (a pro-oxidant) but this will not contribute to their increased risk of $\mathrm{CHD}$.

vegetables. ${ }^{35}$ Absorption of nonhaem iron is inhibited by binding by phytates, which are present in some vegetables and cereals, ${ }^{35}$ and it has been found that iron stores of vegetarians may be reduced especially with a diet based on unleavened unrefined cereals. ${ }^{36}$ The combination in Indians of a more vegetarian diet (see above) and consumption of chapatis would result in lower ferritin values but whether or not there are also other causes is not clear. Lower blood ferritin values in Indians cannot be an explanation for their higher CHD rates, if anything they would be protective, and whether or not they have any health effects is not clear.

The consumption survey in Singapore inquired as to the regular taking of nutritional supplements. ${ }^{26}$ The only ones taken by a significant proportion of the population were multivitamins and vitamin $\mathrm{C}$, which were for men, Indians $9.1 \%$, Malays $8.5 \%$, and Chinese $9.8 \%$, and for women, Indians $9.7 \%$, Malays $4.1 \%$, and Chinese $6.9 \%$. Vitamin A, vitamin E, selenium, and iron were each taken by less than $1 \%$ of the population. This suggests that average vitamin $\mathrm{C}$ from the normal diet is slightly less than indicated by plasma concentrations with the difference varying little by ethnic group.

In conclusion, if vitamin $\mathrm{C}$ and selenium are established as being protective against $\mathrm{CHD}$, lower blood concentrations of these dietary anti-oxidants, particularly in combination, could contribute to the increased risk of Indians for CHD compared with Malays and Chinese in Singapore. Lower blood vitamin C concentrations could contribute to the increased risk for CHD of Malays compared with Chinese. The differences in concentrations, however, suggest that these contributions are unlikely to be great. Vitamin A, vitamin E, and ferritin (iron) would seem to have no part to play in this differential ethnic risk of CHD. The only apparent explanation for the lower blood vitamin C in Indians and Malays is its destruction by the more prolonged cooking at higher temperatures in their cuisines. In Indians, their lower blood selenium is probably because of a lower intake and their much lower blood ferritin because of a lower iron intake and binding of nonhaem iron by phytates in their diet. Funding: The National University of Singapore Heart Study
was funded by the National University of Singapore and the was funded by the National Univer Conflicts of interest: none. 
1 McKeigue PM. Coronary heart disease in Indians, Pakistanis, and Bangladeshis: aetiology and possibilities for nis, and Bangladeshis: aetiology and
prevention. Br Heart 7 1992;67:341-2.

2 Ames BN, Shigenaga MK, Hagen TM. Oxidants, antioxidants, and the degenerative diseases of aging. Proc Natl Acad Sci USA 1993;90:7915-22.

3 Aviram M. Modified forms of low density lipoprotein and atherosclerosis. Atherosclerosis 1993;98:1-9.

4 Oliver MF. Antioxidant nutrients, atherosclerosis, and coronary heart disease. Br Heart $\mathcal{F}$ 1995;73:299-301.

5 Steinberg D. Anti-oxidant vitamins and coronary heart disease. N Engl f Med 1993;328:1487-9.

6 Hennekens CH, Buring JE, Peto R. Antioxidant vitaminsbenefits not yet proven. N Engl F Med 1994;330:1080-1.

7 Gillman MW. Editorial. Enjoy your fruit and vegetables. BMF 1996;313:765-6.

8 Halliwell B. Free radicals, antioxidants, and human disease: curiosity, cause, or consequence? Lancet 1994;344:721-4.

9 van Poppel G, Kardinaal A, Princen H, Kok FJ. Antioxidants and coronary heart disease. Ann Med 1994;26:42934 .

10 The Alpha-Tocopherol, Beta Carotene Cancer Prevention Study Group. The effect of vitamin $\mathrm{E}$ and beta carotene on the incidence of lung cancer and other cand smokers. N Engl F Med 1994;330:1029-35.

11 Hennekens CH, Buring JE, Manson JE, et al. Lack of effect of long-term supplementation with beta carotene on the incidence of malignant neoplasms and cardiovascular disease. N Engl f Med 1996;334:1145-9.

12 Omenn GS, Goodman GE, Thornquist MD, et al. Effects of a combination of beta carotene and vitamin A on lung cancer and cardiovascular disease. N Engl f Med 1996;334: $1150-5$.

13 Salonen JT, Salonen R, Seppanen K, et al. Relationship of serum selenium and antioxidants to plasma lipoproteins, platelet aggregability and prevalent ischaemic heart disease in eastern Finnish men. Atherosclerosis 1988;70:155-60.

14 Salonen JT, Salonen R, Seppanen K, Kantola M, Suntioinen $S$, Korpela $H$. Interactions of serum copper, selenium inen $\mathrm{S}$, Korpela $\mathrm{H}$. Interactions of serum copper, selenium and low density lipoprote

15 Ascherio A, Willett WC. New directions in dietary studies of coronary heart disease. 7 Nutr 1995;125 (suppl 3):647-55s

16 Sullivan JL. Iron and the sex difference in heart disease risk. Lancet 1981;i:1293-4.

17 Burt MJ, Halliday JW, Powell LW. Iron and coronary heart disease. $B M \mathcal{F}$ 1993;307:575-6

18 Hughes K, Lun KC, Yeo PBB. Cardiovascular diseases in Chinese, Malays, and Indians in Singapore. I. Differences in mortality. 7 Epidemiol Community Health 1990;44:24-8.

19 Hughes K, Yeo PPB, Lun KC, et al. Cardiovascular diseases in Chinese, Malays, and Indians in Singapore. II. Differences in risk factor levels. F Epidemiol Community Health 1990;44:29-35.
20 Hughes K, Yeo PPB, Lun KC, Thai AC, Wang KW, Cheah JS. Physical activity in Chinese, Malays and Indians in Singapore. Ann Acad Med Singapore 1990;19:326-9.

21 Hughes K, Yeo PPB, Lun KC, Thai AC, Wang KW, Cheah JS. Obesity and body mass indices in Chinese, Malays and Indians in Singapore. Ann Acad Med Singapore 1990;19: 334-8.

22 Hughes K, Yeo PPB, Lun KC, Thai AC, Wang KW, Cheah JS. Alcohol consumption in Chinese, Malays and Indians in Singapore. Ann Acad Med Singapore 1990;19:330-2.

23 Hughes K, Aw TC, Kuperan P, Choo M. Central obesity, insulin resistance, syndrome $\mathrm{X}$, lipoprotein(a), and cardiovascular risk in Indians, Malays and Chinese in Singapore. 7 Epidemiol Community Health 1997;51:394-9.

24 Liau LS, Lee BL, New AL, Ong CN. Determination of plasma ascorbic acid by high-performance liquid chromatography with ultraviolet and electrochemical detection. $\mathcal{F}$ Chromatogr 1993;612:63-70.

25 Lee BL, Chua SC, Ong HY, Ong CN. High-performance liquid chromatographic method for routine determination of vitamins $\mathrm{A}$ and $\mathrm{E}$ and beta-carotene in plasma. $\mathcal{f}$ Chromatogr 1992;581:41-7.

26 Food and Nutrition Department. Food consumption study 1993. Singapore: Ministry of Health April 1994.

27 Thurnham DI, Davies JA, Crump BJ, Situnayake RD, Davis $M$. The use of different lipids to express serum tocopherol: lipid ratios for the measurement of vitamin $\mathrm{E}$ status. Ann Clin Biochem 1986;23:514-20.

28 Olson JA. Vitamin A, retinoids, and carotenoids. In: Shils ME, Olson JA, Shike M, eds. Modern nutrition in health and disease. Philadelphia: Lea and Febiger, 1994;287-307.

29 Farrell PM, Roberts RJ. Vitamin E. In: Shils ME, Olson JA, Shike $\mathrm{M}$, eds. Modern nutrition in health and disease. Philadelphia: Lea and Febiger, 1994;326-41.

30 Jacob RA. Vitamin C. In: Shils ME, Olson JA, Shike M, eds. Modern nutrition in health and disease. Philadelphia: Lea and Febiger, 1994;432-48.

31 DeMan JM. Principles of food chemistry. NewYork: Van Nostrand Reinhold, 1990:351.

32 Khaw KT, Woodhouse P. Interrelation of vitamin C, infection, haemostatic factors, and cardiovascular disease. BMF 1995;310:1559-63.

33 Levander OA, Burk RF. Selenium. In: Shils ME, Olson JA, Shike M, eds. Modern nutrition in health and disease. Philadelphia: Lea and Febiger, 1994:242-51.

34 Godsland I, Seed M, Simpson R, Broom G, Wynn V. Comparison of haematological indices between women of four ethnic groups and the effect of oral contraception. $\mathcal{F}$ Clin Pathol 1983;36:184-91.

35 Fairbanks VF. Iron in medicine and nutrition. In: Shils ME, Olson JA, Shike M, eds. Modern nutrition in health and disease. Philadelphia: Lea and Febiger, 1994;185-213.

36 Craig WJ. Iron status of vegetarians. Am J Clin Nutr 1994; 59 (suppl 5):1233-7S 